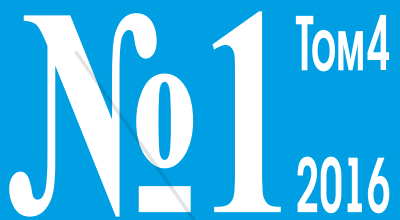

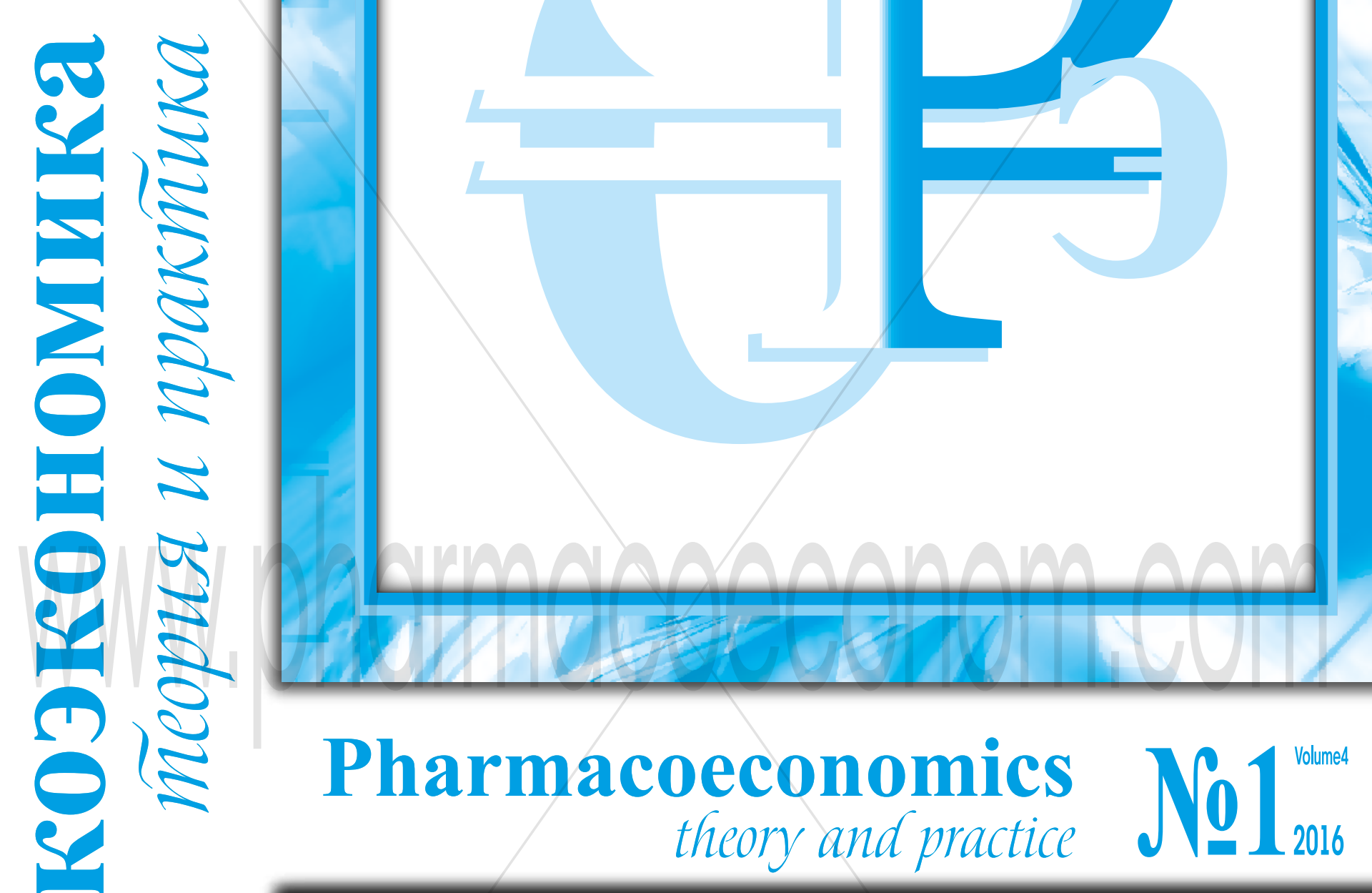

$\square$ МЕТОДОЛОГИЧЕСКИЕ ОСНОВЫ ФАРМАКОЭКОНОМИЧЕСКОГО МОДЕЛИРОВАНИЯ

$\square$ РЕЗУЛЬТАТЫ РОССИЙСКИХ ФАРМАКОЭКОНОМИЧЕСКИХ ИССЛЕДОВАНИЙ

口 МАТЕРИАЛЫ Х НАЦИОНАЛЬНОГО КОНГРЕССА С МЕЖДУНАРОДНЫМ УЧАСТИЕМ «РАЗВИТИЕ ФАРМАКОЭКОНОМИКИ И ФАРМАКОЭПИДЕМИОЛОГИИ В РОССИЙСКОЙ ФЕДЕРАЦИИ» 4-5 апреля 2016 г., г. Нижний Новгород 


\title{
МЕТОД ФИШБЕРНА, МОНТЕ-КАРЛО МОДЕЛИРОВАНИЕ И КЛАССИЧЕСКИЙ МЕТОД ФАРМАКОЭКОНОМИЧЕСКОГО АНАЛИЗА В ОЦЕНКЕ АНТИБИОТИКОТЕРАПИИ ОСТРОГО БРОНХИТА С БРОНХОСПАЗМОМ У ДЕТЕЙ
}

FISHBURNES METHOD, MONTE CARLO SIMULATION AND THE CLASSICAL METHOD OF PHARMACOECONOMIC ANALYSIS IN THE EVALUATION OF ANTIBIOTIC TREATMENT OF ACUTE BRONCHITIS WITH BRONCHOSPASM IN CHILDREN

\author{
Жукова О.В. \\ Zhukova O.V.
}

\section{ГБОУ ВПО «Нижегородская государственная медицинская академия» Минздрава России, 2. Нижний Новгород \\ State Educational Establishment of Higher Professional Training Nizhny Novgorod State Medical Academy of the Ministry of Public Health of the Russian Federation, Nizhny Novgorod}
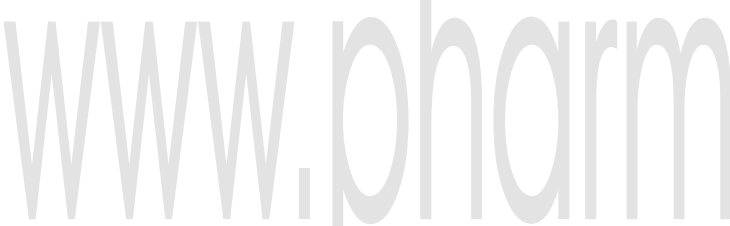

Ключевые слова: антибиотикотерапия, острый бронхит с бронхоспазмом, клинико-экономический анализ, метод Фишберна, Монте-Карло моделирование, метод «затраты-эфффективность».

Цель исследования: оценить клинико-экономическую эфрфективность антибиотикотерапии острого бронхита с бронхоспазмом.

Материалы и методы: для анализа использовались распределение антибиотиков по уровням клинической эфффективности с помощью весовых коэфффициентов по методу Фишберна, метод Монте-Карло симуляция и классический фармакоэкономический анализ проводимой антибиотикотерии. После чего было проведено сопоставление результатов, полученных различными способами, что было сделано впервые. Материалами для исследования служили данные по антибиотикотерапии пациентов, госпитализированных в стационары медицинских организаций с острым бронхитом с бронхоспазмом . В исследование были включены истории болезни 2259 пациентов. Возраст пациентов составил от 0 лет до 18 лет. Для определения весовых коэффрициентов каждого из используемых антибиотиков с последующим их распределением по уровням клинической эсффективности использовался метод Фишберна. В данном исследовании использовались три уровня клинической эффективности, а именно высокий, средний и низкий. Для сопоставления затрат и эффективности сравниваемых курсов терапии острого бронхита с бронхоспазмом были применены классический анализ «затраты-эфрфективность» и метод Монте-Карло симуляция.

Результаты: в итоге было получено, что наибольшей вероятностью наступления положительного клинического эфрфекта из группы цесралоспоринов обладает Цефотаксим (ОАО Биосинтез). С фармакоэкономической точки зрения наиболее эффективным при лечении острого бронхита с бронхоспазмом у детей в условиях стационара являлся Цефтриаксон (ОАО Синтез). Из группы защищенных пенициллинов использовался амоксициллин/клавулановая кислота - оригинальный препарат Аугментин (Smithkline Beecham Pharmaceuticals) и генерический

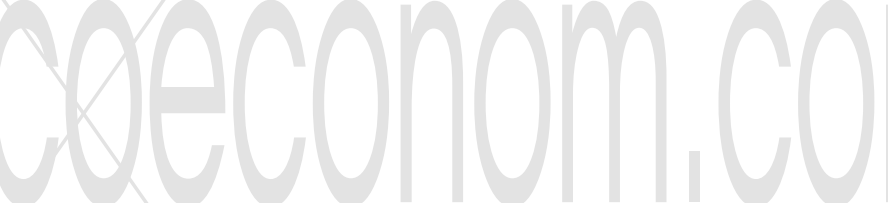

- Амоксиклав (Lek d.d). Эфрфрективность Аугментина составила 0,591, а эффективность Амоксиклава - 0,530. Стоимость курса Аугментина составила 106,26 руб., стоимость курса Амоксиклава - 103,50 руб. Наиболее целесообразным оказалось использование Аугментина. Курс терапии Аугментином характеризовался меньшим значением коэфффициента CER относительно Амоксиклава. Мы получили, что курс Азитромицина (ЗАО Вертекс) с фрармакоэкономической точки зрения оказался наиболее целесообразным из антибиотиков - макролидов при терапии острого и рецидивирующего обструктивного бронхита. Однако данный антибиотик согласно классификации по клинической эфффективности по Фишберну относился к среднему уровню. К высокому уровню относились Сумамед, Азитрал, Хемомицин, Клацид, Зитроцин и Клабакс. Клацид и Клабакс были исключены в ходе фрармакоэкономического анализа. Наибольшее значение коэффициента ICER было получено для Сумамеда и составило 39 367,50 руб. Для Сумамеда было характерно и самое высокое значение клинической эффрективности. K тому же Сумамед является оригинальным препаратом азитромицина. Азитрал и Хемомицин имели согласно полученным данным наименьшие после Азитромицина значения коэфффициента ICER (1151,67 руб. и 1812,22 руб. соответственно). Таким образом, данные лекарственные препараты оказались наиболее оптимальными по результатам клинико-экономического анализа. Азитрал и Хемомицин являются также наиболее оптимальными антибиотиками в группе макролидов по результатам имитационного моделирования Монте-Карло симуляция.

Заключение: в результате проведенного анализа было получено, что при лечении острого бронхита с бронхоспазмом у детей в условиях стационара наиболее эфрфективным из группы цефралоспоринов оказался Цефотаксим, из группы макролидов - Азитрал и Хемомицин. Данные препараты согласно классификации по методу Фишберна относились к высокому уроню клинической эффрективности, следуя сразу за Сумамедом по вероятности наступления положительного клинического эфрфекта. 